UNIVERSIDAD DE GRANADA

FACULTAD DE MEDICINA

TRABAJO DE FIN DE MÁSTER

Máster: AVANCES EN RADIOLOGÍA DIAGNÓSTICA Y TERAPÉUTICA Y MEDICINA FISICA

CURSO 2014-2015

\title{
PAPEL DE LOS microRNAs EN LA RESPUESTA AL TRATAMIENTO DE LA ARTRITIS REUMATOIDE
}

María Pavo Blanco

MIR Reumatología

H.U. San Cecilio de Granada

Tutora: Mercedes Villalobos 


\section{ÍNDICE}

\section{INTRODUCCIÓN}

1.1. Artritis Reumatoide (AR)
a) Concepto
b) Fisiopatología
c) Epidemiología
d) Etiología
e) Inmunopatología
f) Manifestaciones clínicas
g) Diagnóstico
h) Evolución de la enfermedad
i) Objetivo terapéutico
j) Tratamiento

1.2. MicroRNA
a) Concepto
b) Biosíntesis
c) Papel en la AR. Tipos.

\section{PROYECTODE INVESTIGACIÓN}

2.1. Título del proyecto

2.2. Palabras clave

2.3. Resumen

2.4. Hipótesis

2.5. Objetivos:
a) Primarios
b) Secundarios 
2.6. Metodología

a) Diseño del estudio

b) Población de estudio

c) Criterios de inclusión

d) Criterios de exclusión

e) Tamaño muestral

f) Recogida de datos

g) Análisis de datos

h) Limitaciones del estudio

i) Aspectos éticos de la investigación

\section{BIBLIORAFÍA.}




\section{INTRODUCCIÓN}

\subsection{Artritis reumatoide:}

a) Concepto:

La artritis reumatoide (AR) es una enfermedad sistémica de carácter autoinmune que se caracteriza por una inflamación crónica de las articulaciones y vainas tendinosas de la membrana sinovial. En la mayoría de los pacientes el curso es progresivo y conduce a la lesión estructural articular, el deterioro funcional, la disminución de la calidad de vida y un aumento de la morbilidad y la mortalidad. [1,2].

b) Fisiopatología:

La fisiopatología de esta enfermedad se basa en una activación anómala de procesos normalmente implicados en las respuestas inmune e inflamatoria defensivas.

La membrana sinovial es el tejido más específicamente afectado por la AR. Esta membrana está constituida por tejido conectivo que limita la cavidad articular, ocupada por el líquido sinovial, y que envuelve la articulación prolongándose hasta el margen de la unión osteocartilaginosa. En ella se observan pequeños vasos y una capa celular limitante formada por macrófagos y fibroblastos, que en esta localización se denominan sinoviocitos de tipo A o B.

Aunque la sinovial es el foco principal de lesión, en la AR se producen cambios sistémicos que implican a todos los compartimientos del sistema inmune, manifestaciones inflamatorias específicas en otros órganos y alteraciones sistémicas no específicas, consecuencia de la inflamación sistémica $[2,3,4,5]$.

c) Epidemiología:

La AR afecta al 0,5\% de la población y es más frecuente en mujeres, en una proporción aproximada de 3:1. Su comienzo puede ocurrir a cualquier edad, aunque es más frecuente entre los 40-60 años. La incidencia aumenta en familiares (2-3 veces), y en gemelos monocigóticos tiene una concordancia del 20-30\%, reflejando un componente genético que sigue un modelo de 
herencia poligénico [1,2]. En fumadores, el riesgo de padecer AR es 1.5-2 veces mayor y no hay muchos más datos epidemiológicos que impliquen a otros factores causales exógenos.

\section{d) Etiología:}

La causa de la AR es desconocida y se cree que aparece por la acción de agentes ambientales (infecciones, tabaquismo, etc.) sobre un terreno genético predispuesto.

Los factores genéticos identificados incluyen múltiples genes implicados en la respuesta inmune. Los más conocidos son los relacionados con el complejo mayor de histocompatibilidad HLA-DRB1, en concreto DR4 y DR1, que constituyen la mayor influencia genética de la AR.

Se conoce más de una treintena de genes cuyas variantes se han asociado a susceptibilidad y/o gravedad de la enfermedad y que, en general, se relacionan con funciones implicadas en la respuesta o activación de los linfocitos T o con elementos relacionados con la regulación de respuestas celulares asociadas a la respuesta inmune e inflamatoria. Aunque la base genética es evidente, aún no es posible aplicarla a la predicción clínica, ya que la mayoría de las variantes aportan un riesgo relativo bajo respecto a la población normal [2].

e) Inmunopatología:

La AR se considera una enfermedad autoinmune y, en la mayoría de los pacientes, se detecta una respuesta de autoanticuerpos que reconocen determinados autoantígenos. La generación inapropiada de células B autorreactivas y sus respectivos autoanticuerpos es la alteración del sistema inmune más evidente, pudiéndose detectar éstos antes de que aparezca la enfermedad. Los anticuerpos más importantes son el denominado factor reumatoide (FR), que reconoce como autoantígeno la región constante $(\mathrm{Fc})$ de la $\mathrm{IgG}$, y el antipéptido citrulinado (anti -CCP), que reconoce diferentes proteínas en forma citrulinada, en las que se han transformado enzimáticamente (deiminación) sus residuos arginina en citrulina.

Estas dos respuestas son bastante específicas y se postula que la formación local o sistémica de inmunocomplejos, su acumulación articular, y la activación local de factores del 
complemento y de células efectoras, a través de receptores celulares de inmunoglobulinas (FcyR) o de receptores de factores del complemento (C3/C5aR), son un mecanismo central en la patogenia de la inflamación articular crónica. La activación de estos receptores en macrófagos induciría la producción de citoquinas y otros mediadores [4].

El factor de necrosis tumoral alta (TNF-alfa) juega un papel principal en la patogenia de la enfermedad, ya que promueve la activación de macrófagos y otras células para segregar citoquinas proinflamatorias (interleuquina (IL)-1, IL-2, IL-6 e IL-8), la activación de células T, así como induce a las células endoteliales la expresión de moléculas de adhesión. Además, TBFalfa está involucrado en la diferenciación y maduración de los osteoclastos (principal célula involucrada en la destrucción articular) y estimula a los fibroblastos, osteoclastos y condrocitos para producir proteinasas, las cuales destruyen el cartílago articular y el hueso [5].

Recientemente se ha demostrado que estas respuestas celulares pueden perpetuarse en el tiempo por mecanismos epigenéticos. Con el paso de los años, se ha ido estableciendo que las alteraciones en el nivel de expresión de diferentes microRNAs pueden contribuir al desarrollo de autoinmunidad, particularmente en la AR [2].

f) Manifestaciones clínicas:

La artritis reumatoide (AR) es una enfermedad inflamatoria crónica que afecta preferentemente a las articulaciones de forma simétrica, pero que también puede dañar los órganos internos, por lo que debe considerarse como una enfermedad sistémica.

Los síntomas habituales de esta enfermedad son:

$\S$ Dolor. Es de ritmo inflamatorio y se exacerba con el reposo.

$\S \quad$ Inflamación articular.

$\S \quad$ Rigidez articular. 
$\S$ Debilidad muscul ar y atrofia. Se deben al desuso de las articulaciones y conllevan un aumento del grado de incapacidad.

$\S$ Deformidad articular.

Como se trata de una enfermedad sistémica, puede aparecer manifestaciones extraarticulares y comorbilidades relacionadas con la propia enfermedad o con los tratamientos.

$\S$ Pulmón: puede aparecer pleuritis, nódulos parenquimatosos o necrobióticos, enfermedad pulmonar intersticial. Con menor frecuencia, bronquiolitis obliterante, bronquiectasias, síndrome de Caplan (nódulos pulmonares con sílice en pacientes con AR y neumoconiosis) e hipertensión pulmonar aislada.

$\S$ Piel: nódulos subcutáneos, úlceras cutáneas, atrofia cutánea.

$\S$ Corazón: pericarditis, enfermedad cardiovascular, etc.

$\S$ Sistema nervioso: síndrome del túnel carpiano, subluxación atloido-axoidea, mononeuritis múltiple.

$\S$ Órganos hematopoyéticos: síndrome de Felty (asociación de AR con neutropenia y esplenomegalia), leucemia de linfocitos grandes granulares, linfomas.

$\S \quad$ Ojos: síndrome de Sjögren, escleritis, cataratas.

$\S$ Riñón: glomerulonefritis focal mesangioproliferati va o vasculitis renal.

$\S$ Gastrointestinal: úlcera gastroduodenal, hemorragias digestivas y perforación.

$\S \quad$ Vasculitis.

$\S \quad$ Músculo: debilidad, miositis.

$\S$ Hueso: osteoporosis, fracturas (principalmente vertebrales).

$\S$ Cáncer: la incidencia está aumentada, siendo más frecuente el linfoma.

$\S$ Infecciones bacterianas: son de las complicaciones más frecuentes. Se relacionan con la propia actividad de la enfermedad, así como con el uso de corticoides y terapias biológicas. 
$\S$ Amiloidosis [6-10].

g) Diagnóstico:

Los criterios para establecer el diagnóstico de la AR están basados en una historia clínica precisa, un examen físico completo, pruebas de laboratorio y exclusión de otros diagnósticos.

Los criterios diagnósticos de la ACR/EULAR 2010 fueron creados por un grupo de expertos de Norteamérica y Europa con el objetivo de detectar a los pacientes de forma temprana y así instaurar un tratamiento precoz (Tabla 1).

Entre los datos de laboratorio que pueden aparecer en la AR son: anemia, aumento de los reactantes de fase aguda como la proteína C reactiva (PCR) y la velocidad de sedimentación globular (VSG), presencia de anticueropos como el factor reumatoide (FR, que tiene una alta sensibilidad, pero no es específico de esta enfermedad), el antipéptido citrulinado (ACPA, con una especificidad de alrededor del 95\%) y anticuerpos antinucleares (ANAS). También se puede hacer un análisis del líquido sinovial, observándose un exudado inflamatorio, con alto recuento de leucocitos (principalmente polimorfonucleares).

Entre los estudios de imagen, son de utilidad en el diagnóstico los siguientes:

i. Radiografía: se puede apreciar aumento de partes blandas, osteopenia yuxtaarticular, estrechamiento simétrico del espacio articular, erosiones óseas, pannus sinovial, geodas intraóseas, anquilosis.

ii. Ecografía: es la prueba de mayor sensibilidad diagnóstica, principalmente en los primeros estadios de la enfermedad. Además, uede dar información del grado de sinovitis articular. 
iii. Resonancia magnética: es también de gran utilidad, principalmente para la detección de complicaciones como la necrosis avascular, fracturas por estrés, quistes sinoviales, etc $[6-10,18]$.

\begin{tabular}{|c|c|}
\hline \multicolumn{2}{|c|}{$\begin{array}{c}\text { Criterios de la American Rheumatism Association/European League Against Rheumatism (ACR/EULAR) } 2010 \\
\text { para la clasificación de artritis reumatoide }\end{array}$} \\
\hline $\begin{array}{l}\text { Población diana: } \\
\text { 1. Sinovitis (inflanación) confirmada on al manos } 1 \text { articulacion } \\
\text { 2. Sinovinis no explicada por otra enfermedad } \\
\text { Se precisa un indice } \geq 6 / 10 \text { para la clasificación de AR definiala }\end{array}$ & \\
\hline Afectación articular" & \\
\hline 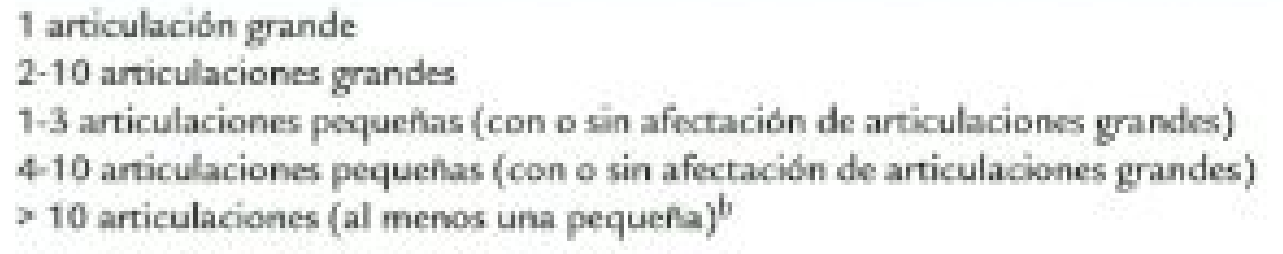 & $\begin{array}{l}0 \\
1 \\
2 \\
3 \\
5\end{array}$ \\
\hline Serologia & \\
\hline $\begin{array}{l}\text { ACPA y FR ambos negativos } \\
\text { ACPA o FR ambos positinos (titulos bajos) } \\
\text { ACPA o FR ambes positivos (titulos altos) }\end{array}$ & $\begin{array}{l}0 \\
2 \\
3\end{array}$ \\
\hline Reactantes de frese aguda & \\
\hline $\begin{array}{l}\text { PCR y VSG nomales } \\
\text { PCR o VSG elevedos }\end{array}$ & $\begin{array}{l}0 \\
1\end{array}$ \\
\hline Durnción de los síntomats & \\
\hline $\begin{array}{l}46 \text { semanas } \\
26 \text { semanas }\end{array}$ & $\begin{array}{l}0 \\
1\end{array}$ \\
\hline
\end{tabular}

Tabla 1. Manual SER $6^{\mathrm{a}}$ Edición. (a) La afectación articular se refiere a cualquier articulación dolorosa o inflamada en la exploración, que puede ser confirmada por pruebas de imagen. Las articulaciones interfalángicas distales, primeras carpometacarpianas y primeras metatarsofalángicas son excluidas de la valoración.

- Articulaciones grandes: hombros, codos, caderas, rodillas y tobillos.

- Articulaciones peque ñas: metacarpofalángicas, interfalángicas proximales, $2{ }^{a}{ }^{a}$ a $5 .^{a}$ metatarsofalángicas, interfalángicas del pulgar y muñecas.

(b) En esta categoría, al menos una articulación afectada debe ser peque ña. Pue de incluir combinaciones de grandes y pequeñas, así como otras articulaciones en distintas localizaciones (temporomandibular, acromioclavicular, esternoclavicular, etc.).

(c) Seconsideran títulos bajos valores $\leq 3$ veces mayores que el límite superior de la normalidad. títulos altos, valores $>3$ veces el límite superior de la normalidad. En caso de que solo conozcamos si el factor reumatoide es positivo o negativo (y no su titulación), un resultado positivo se puntuará como positivo-bajo.

ACPA: anticuerpos antipéptidos citrulinados; PCR: proteína C reactiva; VSG: velocidad de sedimentación globular.

\section{h) Evolución de la enfermedad}

Hay una gran variabilidad en el curso clínico, tasa de progresión y extensión del daño articular en pacientes con AR. Se ha estimado que el $70 \%$ de los pacientes presenta un curso progresivo que se asocia con destrucción articular considerable en pocos años desde el inicio de 
la enfermedad, mientras que en otros la gravedad de la inflamación y de la progresión del daño articular es más lenta, cursando con brotes de artritis que van seguidos de remisiones de duración variable. Identificar a los pacientes que desarrollarán una enfermedad rápidamente progresiva es importante, pues una intervención inmediata y agresiva ofrece una gran oportunidad para cambiar el curso natural de la enfermedad, mejorando los desenlaces a largo plazo en este grupo de riesgo.

Los factores pronósticos desfavorables más fiables son: la elevación de los reactantes de fase aguda (RFA), un elevado número de articulaciones inflamadas, la presencia y el título de FR y ACPA, el epítopo compartido, la existencia de erosiones y el índice de daño radiológico al inicio de la enfermedad.

Otros factores que se han identificado como predictores de mayor incapacidad funcional son: el sexo femenino, la edad avanzada, el tabaquismo activo, un alto número de articulaciones dolorosas, la elevación de reactantes de fase aguda, el índice HAQ (Health Assesment Questionaire, cuestionario para evaluar la discapacidad funcional) basal por encima de $1 \mathrm{y}$ la presencia de erosiones óseas (6-10).

i) Objetivo terapéutico:

El tratamiento de la AR debe dirigirse a disminuir al mínimo la actividad inflamatoria, evitar la progresión de la lesión estructural articular y sus consecuencias.

El objetivo terapéutico debe ser alcanzado, al menos parcialmente, a los tres meses y, como máximo, a los seis meses. Durante este periodo los pacientes deben ser valorados con regularidad (de 1 a 3 meses) para intensificar o modificar el tratamiento si no se alcanza el objetivo. 
El objetivo terapéutico debe ser la remisión de la enfermedad, entendida en sentido estricto como la ausencia de síntomas clínicos, de progresión del daño estructural o discapacidad, y evitar las comorbilidades a largo plazo [11-16].

Para valorar la remisión de la enfermedad, la ACR y la EULAR han propuesto una serie de criterios y han establecido unos índices compuestos que valoran la actividad inflamatoria de la enfermedad. Entre estos índices, el más extendido es el DAS-28, que valora de forma asimétrica los cuatro componentes que lo forman. La fórmula matemática de la que se deriva este índice es: DAS28 $=0,56 \times \mathrm{NAD}+0,28 \times \mathrm{NAT}+0,7 \times \ln (\mathrm{VSG})+0,014 \times \mathrm{GH}$ donde $\mathrm{NAD}$ es el recuento de dolor en 28 articulaciones, NAT es el recuento de tumefacciones en las mismas 28 articulaciones, ln(VSG) es el logoritmo neperiano de la velocidad de sedimentación globular y GH (global health) es la valoración del estado de salud y la actividad de la enfermedad estimados por el propio paciente en una escala visual de $100 \mathrm{~mm}$, en la que los valores más altos significan mayor acti vidad o peor estado de salud [19].

j) Tratamiento:

- Tratamiento sintomático: antiinflamatorios no esteroideos (AINEs), glucocorticoides, etc.

- Tratamiento para enlentecer o detener la progresión de la AR:

1. Fármacos antirreumáticos modificadores de la enfermedad (FAMEs).

Son los fármacos de primera elección en la AR. Los más relevantes, atendiendo a su rapidez de acción, eficacia clínica, influencia en la evolución de las lesiones radiográficas y tolerabilidad, son el metotrexato (MTX), la sulfasalazina y la leflunomida. Otros FAMEs, como los antipalúdicos, el aurotiomalato sódico o la ciclosporina, también han demostrado ser útiles, pero no se deben considerar indispensable su uso antes de instaurar la terapia biológica. Para conseguir el objetivo terapéutico, se recomiendan las siguientes pautas de tratamiento:

1.1. MTX: es el fármaco de primera elección. Se administra en escalada rápida de dosis: 7,5 mg semanales durante el primer mes. Si al mes persiste la artritis en cualquier localización, se aumenta a 15 mg semanales. Si al mes 
todavía persiste la artritis, se aumenta a $20 \mathrm{mg}$. Si tras 2 meses con una dosis de $20 \mathrm{mg}$ semanales no se ha obtenido el objetivo terapéutico, está indicado el cambio de tratamiento. Se recomienda añadir suplementos de ácido fólico (5-10 mg semanales).

1.2. Leflunomida: se administra $20 \mathrm{mg} /$ día durante 3 meses.

1.3. Sulfasalazina: $2 \mathrm{~g} /$ día durante 3 meses.

\section{Terapia biológica:}

Es evidente que la disponibilidad cada vez mayor de agentes biológicos ha mejorado sensiblemente nuestra capacidad de inducir remisión en muchos pacientes con AR y de modificar significativamente su evolución en otros. No obstante, por su alto coste y la todavía limitada información sobre sus posibles efectos secundarios a largo plazo, es necesario evitar su uso indiscriminado [11].

\subsection{Antagonistas del factor de necrosis tumoral alfa (antiTNF-alfa):}

Actualmente disponemos de tres: la proteína de fusión con el receptor soluble (etanercept) y 2 anticuerpos monoclonales (infliximab y adalimumab). Se emplean tanto en AR resistentes a FAMEs como en los pacientes con AR de inicio reciente. En estudios controlados los 3 han demostrado una alta eficacia en mejorar los parámetros clínicos de actividad y en producir el enlentecimiento o la detención de las lesiones radiográficas. No hay datos que avalen la superioridad de un antagonista del TNF sobre otro, por lo que la elección concreta depende del criterio médico y de las circunstancias particulares de cada paciente. No obstante, como presentan diferentes estructura, antigenicidad y mecanismos de acción, la falta de respuesta a uno de ellos no implica en modo alguno la ineficacia de otro. Aunque se pueden administrar en monoterapia, recientes estudios controlados y a doble ciego indican que ambos son más eficaces cuando se administran junto con MTX en dosis altas (15 a $20 \mathrm{mg}$ semanales). Por tanto, la combinación de antiTNF con MTX en dosis terapéuticas es actualmente la pauta más aconsejable, a no ser que el paciente presente toxicidad o intolerancia al MTX [11-16]. 
Ha demostrado su eficacia frente a placebo tanto en su acción contra los síntomas de la AR como en su progresión radiográfica. Aunque nunca se lo ha comparado en estudios controlados con los antagonistas del TNF, por los datos publicados existe la percepción generalizada de que su eficacia es inferior [13-14].

\subsection{Anticuerpo monoclonal quimérico, específico contra el CD20 de las células B (rituximab). \\ 2.4. Proteína de fusión constituida por el receptor CTLA4-Ig unido a Ig (abatacept), unido a IgG humana.}

Estos 3 últimos agentes son potencialmente útiles como terapia biológica inicial en pacientes en que esté contraindicado el tratamiento con antagonistas del TNF (enfermedades desmielinizantes, insuficiencia cardíaca).

Actualmente, por su mayor tendencia a producir infecciones graves o la falta de información suficiente al respecto, se desaconseja la combinación de un antagonista del TNF con cualquier otro agente biológico [11-16]. 


\section{2. microRNA (miRNA):}

\section{a) Concepto}

Los miRNA son una extensa familia de ARNs no codificantes constituidos aproximadamente por 21 nucleótidos que regulan la expresión de genes a nivel postranscripcional. Fueron descubiertos a principios del año 2000 y su importancia ha sido estudiada en multitud de procesos celulares [2].

b) Biosíntesis

Los miRNA se procesan desde precusores inmaduros (pri-miRNA) a partir de genes independientes, o a partir de intrones de genes que codifican proteínas. Los miRNA se doblan adquiriendo estructura secundaria hairpin que sirven de sustrato para Drosha y Dicer, ambas pertenecientes a la familia de enzimas RNAasas. El pri-miRNA es procesado por Drosha dando lugar a un oligonucleótido de alrededor 70 pares de bases (pre-miRNA) que es exportado del núcleo al citoplasma. Dicer procesa el pre-miRNA a un dúplex miRNA/miRNA de 20 pares de bases, el miRNA maduro. Una de las hebras del dúplex es integrada al complejo miRISC (miRNA-induced silencing complex: complejo de silenciamiento inducido por miRNAs). En función de la complementariedad interaccionará con un determinado RNA mensajero para reprimir su función. Puede evitar el que sea traducido y provocar la degradación exonucleolítica de la cola de poliA del RNA mensajero cuando la complementariedad es imperfecta con la región 3'UTR. Cuando la complementariedad es perfecta, puede provocar la degradación endonucleolítica del RNA mensajero por parte de AGO2 (Argonaute proteins). De la misma manera que cualquier gen, los genes que codifican microRNAs pueden sufrir procesos de regulación trascripcional tales como metilación de sus promotores, etc [2].

La funcionalidad de los microRNAs puede ser estudiada gracias a los algoritmos bioinformáticos que predicen los RNA mensajeros (RNAm) dianas de los miRNAs estudiados. 
En ellos, se analiza la probabilidad de interacción teniendo en cuenta distintos parámetros tales como complementariedad, la estructura secundaria formada, la temperatura de fusión, etc. Gracias a estas herramientas se pueden predecir dianas potenciales que son silenciadas por el efecto de los microRNAs [20,21].

c) Papel en la AR:

La literatura científica ha demostrado que una gran variedad de miRNAs presentan una alteración en su regulación en pacientes con AR.

El dato inicial que propuso un vínculo entre miRNAs y la patogénesis de la AR fue obtenido en 2007, al hallar en pacientes con AR anticuerpos contra antígenos GW, que se relacionan con la expresión de miRNAs . Más tarde, en 2008, Stanczyk et al demostró cambios significativos en los niveles de expresión de miRNA en las células de las articulaciones reumatoides. Los posteriores estudios fueron encaminados a analizar la alteración en la regulación de la expresión de miRNAs tanto en articulaciones inflamados como en sangre periférica en pacientes con AR. Sorprendentemente, en fluidos corporales, los miRNAs muestran una alta estabilidad desde que se presentan como complejos con proteínas o en microvesículas, lo cual previene su degradación por RNasas. De este modo, diferentes miRNAs son buenos candidatos para la sospecha diagnóstica, la monitorización de la enfermedad y otras aplicaciones clínicas.

Los miRNAs funcionan predominantemente como reguladores negativos de la expresión de genes diana, bloqueando la traducción de proteínas o a través de la escisión directa de los RNA mensajeros. Sin embargo, existe evidencia de que también pueden actuar como reguladores positivos.

Así, los miRNAs constituyen una de las más importantes clases de moléculas reguladoras de genes. 
Los tipos de miRNAs que más se han relacionado con la AR y más profundamente se han estudiado son miR-16, miR-146a y miR-155. Otros que también tienen una gran implicación en la patogénesis de la AR son: miR-21, miR-22, miR-23, miR-30a, miR-24, miR26a, miR-34a/b, miR-124a, miR-125a/b, miR-126, miR-132, miR-133 ${ }^{\mathrm{a}}$, etc [2,20-27].

v miR-16: su sobreexpresión ha sido detectada en células mononucleares de sangre periférica (PBMCs), plasma y fluidos sinoviales de pacientes con AR. Sus niveles se incrementan cuando la enfermedad está activa, correlacionándose con el valor de DAS-28. Por eso, miR-16 es un buen biomarcador de actividad de la AR. miR-16 ha demostrado actuar sobre el TNF-alfa, una de las moléculas proinflamatorias claves en la AR, por lo que este miRNA tiene un papel importante en la patogénesis de esta enfermedad.

V miR-146a: es uno de los más estudiados en la AR. El incremento de la expresión de los niveles de este ha sido documentado en líquido sinovial, tejido sinovial, PBMCs, fibroblastos sinoviales de la AR (RAFS) y sangre periférica de pacientes con AR. Se ha demostrado que mirR-146a puede inhibir la respuesta mediada por las células $\mathrm{T}$ y participar en la actividad supresora de las células T reguladoras, dos pasos importantes en la patogénesis de la AR. Existe controversia sobre si se relaciona con la actividad de la enfermedad. En algunos estudios, como los de Pauley et al así y Abou-zeid et al, los niveles de miR-146a fueron positivamente correlacionados con PCR, VSG, DAS-28 y concentración de TNF-alfa.

Se ha sugerido que miR-146a está fuertemente implicado en el desarrollo de la AR, actuando sobre múltiples genes dianas que están relacionados con la inflamación y la apoptosis.

V miR-155: su expresión está aumentada en tejido y líquido sinoviales, RASFS, PBMCs, macrófagos sinoviales, y sangre periférica de pacientes con AR. Los datos obtenidos sugieren que podría tener un importante rol en la inhibición de 
la vía pro-inflamatoria. Los ligandos del receptor Toll-like y citoquinas, como IL-10, podrían regular la expresión de mir155, así como éste actua cmo un potente regulador de la expresión de numerosas citoquinas implicadas en la patogénesis de la AR, como son IL-1beta, IL-6, IL-8, TNF-alfa [2-20-23].

- $\quad$ MicroRNA como biomarcadores:

Los miRNAs han sido determinados en múltiples tejidos de la AR. Consecuentemente, su detección en sangre periférica o en tejidos inflamados se han considerado muy útiles como biomarcadores en la AR.

Los niveles de miRNA en plasma son frecuentemente más elevados que en líquido sinovial. Además, su detección en sangre ofrece una serie de ventajas respecto a otros tejidos: los microRNAs son más estables en este fluido, se trata de una técnica no invasiva, son fáciles de analizar los microRNA (mediante una ténica de PCR), ofrece seguridad diagnóstica (cuando se combina el análisis de varios miRNAs), constituyen un biomarcador potencial para el diagnóstico temprano y la monitorización de la efectividad del tratamiento [22].

Revisado el estado actual del tema, consideramos necesario un estudio que valore este aspecto en los pacientes de nuestro hospital, ya que podrían beneficiarse de un tratamiento efectivo precozmente. En este sentido, presentamos el siguiente proyecto de investigación. 


\section{PROYECTO DE INVESTIGACIÓN:}

2.1. Título del proyecto:

MicroRNA-146 como biomarcador de respuesta al tratamiento con agentes antiTNF-alfa en la artritis reumatoide.

\subsection{Resumen:}

Las terapias biológicas han revolucionado el tratamiento de la artritis reumatoide (AR), produciendo un cambio muy importante en el curso de la enfermedad. Sin embargo, en la actualidad, el mayor desafío continúa siendo identificar biomarcadores para dirigir el tratamiento a un grupo seleccionado de pacientes. Los microRNAs (miRNAs) circulantes representan un grupo de moléculas cuya expresión está alterada en la AR. Se ha demostrado que los niveles de determinados miRNAs, como el miR-146 aue es uno de los más profundamente estudiados, están significativamente aumentados en los pacientes con AR respecto a la población sana. Además, se ha demostrado que miR-146a se correlaciona con la actividad inflamatoria de la enfermedad. En este estudio, se pretende cuantificar los niveles de miR-146 ${ }^{\mathrm{a}}$ en sangre periférica en pacientes con AR de la práctica clínica habitual, que van a ser sometidos a terapias antiTNF- alfa (abatacept, infliximab, etanercept) para evaluar su valor predictivo como biomarcador de respuesta al tratamiento.

\subsection{Introducción:}

La artritis reumatoide (AR) es una enfermedad inflamatoria sistémica de carácter autoinmune que afecta principalmente al cartílago articular y al hueso. Su etiología es aún desconocida. Las principales características de su patogénesis son la inflamación crónica, la hiperplasia sinovial y la erosión del cartílago articular dando lugar a la inflamación y 
destrucción articular. Por otro lado, el estado proinflamatorio sistémico puede dar lugar a manifestaciones extraarticulares.

La instauración de un tratamiento precoz puede prevenir el desarrollo de una discapacidad importante, así como importantes beneficios en la calidad de vida de los pacientes.

El factor de necrosis tumoral alta (TNF-alfa) juega un papel principal en la patogenia de la enfermedad, ya que promueve la activación de macrófagos y otras células para segregar citoquinas proinflamatorias (interleuquina (IL)-1, IL-2, IL-6 e IL-8), la activación de células T, así como induce a las células endoteliales la expresión de moléculas de adhesión. Además, TBFalfa está involucrado en la diferenciación y maduración de los osteoclastos (principal célula involucrada en la destrucción articular) y estimula a los fibroblastos, osteoclastos y condrocitos para producir proteinasas, las cuales destruyen el cartílago articular y el hueso.

La introducción de las terapias anti- TNF han revolucionado el tratamiento de la AR, produciendo un cambio sustancial en el curso de la enfermedad. Ahora bien, muchos pacientes no responden a estas terapias. La respuesta al tratamiento es multifactorial; sin embargo, determinadas variaciones en genes o su expresión pueden ayudar a identificar a los más propensos a responder.

Recientemente, el descubrimiento de alteraciones epigenéticas ha constituido un paso importante en el conocimiento de la patogenia de esta enfermedad. Estos mecanismos epigenéticos juegan un papel crucial en el desarrollo de la AR. Esto nos hace pensar que pueden contribuir como biomarcadores para el diagnóstico precoz de la enfermedad y de respuesta al tratamiento. Los mecanismos epigenéticos que han sido evaluados son la metilación del ADN, la modificación de histonas y la expresión y función de los microRNAs.

Los microRNAs son pequeñas secuencias de ARN no codificante (21-22 nucleótidos) que, dependiendo del apareamiento de bases con el ARN mensajero (ARNm), media la escusión, la represión o la desestabilización del ARNm. 
Está aumentando el número de estudios que demuestran que la disregulación en la expresión de microRNAs en células mononucleares de sangre periférica, linfocitos $\mathrm{T}$, fibroblastos sinoviales y otras contribuyen a la inflamación, degradación de la matriz extracelular y el comportamiento invasivo de las células residentes de la articulación.

Se ha establecido que los microRNA pueden ser aberrantemente expresados en los diferentes estadios de la enfermedad, permiti endo que puedan ayudar a monitorizar la acti vidad de la enfermedad. De este modo, la detección de alteraciones en la expresión de determinados microRNA podría servir como predictores de respuesta al tratamiento [2, 20-27].

2.4. Hipótesis: la expresión de miR-146a en los pacientes con artritis reumatoide puede predecir la respuesta al tratamiento con agentes antiTNF -alfa.

\subsection{Objetivos:}

\subsubsection{Primarios:}

- Incluir a pacientes con artritis reumatoide que vayan a ser sometidos a terapia biológica y evaluar si la expresión de miR-146a influye o no en la respuesta al tratamiento con antiTNF-alfa.

\subsubsection{Secundarios:}

- Determinar si los niveles de miR-146 se correlacionan con la actividad inflamatoria de la enfermedad.

- Valorar si existe modificación en la expresión de miR-146a cuando existe respuesta al tratamiento.

- Examinar otros factores que puedan influir en la respuesta al tratamiento con antiTNF-alfa.

\subsection{Metodología:}

a) Diseño del estudio: 
Se trata de un estudio de cohortes prospectivo que incluirá a los pacientes con artritis reumatoide que vayan a ser sometidos a terapia con antiTNF-alfa. Se valorará la respuesta al tratamiento en función de la expresión de miRNA-146 .

El diagnóstico de AR se realizará según los criterios de la American Rheumatism Association y la European League Against Rheumatism (ACR/EULAR) de 2010 (tabla $1)$.

\begin{tabular}{|c|c|}
\hline \multicolumn{2}{|c|}{$\begin{array}{l}\text { Criterios de la American Rheumatism Association/European League Against Rheumatism (ACR/EULAR) } 2010 \\
\text { para la clasificación de artritis reumatoide }\end{array}$} \\
\hline 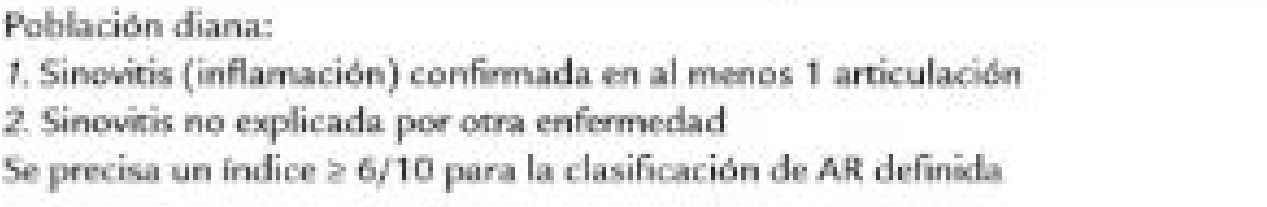 & \\
\hline \multicolumn{2}{|l|}{ Afectación articular" } \\
\hline 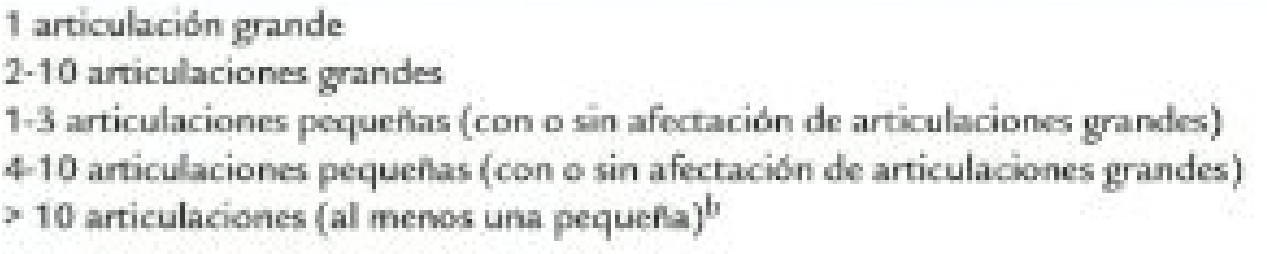 & $\begin{array}{l}0 \\
1 \\
2 \\
3 \\
5\end{array}$ \\
\hline \multicolumn{2}{|l|}{ Serologia } \\
\hline $\begin{array}{l}\text { ACPA y FR ambos nogativos } \\
\text { ACPA o FR ambos positios (tifulos bajos) } \\
\text { ACPA o FR ambes positivos (titulos altos) }\end{array}$ & $\begin{array}{l}0 \\
2 \\
3\end{array}$ \\
\hline \multicolumn{2}{|l|}{ Reactantes de fase aguda } \\
\hline $\begin{array}{l}\text { PCR y VSG nomales } \\
\text { PCR o VSG elevedos }\end{array}$ & $\begin{array}{l}0 \\
1\end{array}$ \\
\hline \multicolumn{2}{|l|}{ Durnción de los síntomis: } \\
\hline $\begin{array}{l}26 \text { semanas } \\
26 \text { semanas }\end{array}$ & $\begin{array}{l}0 \\
1\end{array}$ \\
\hline
\end{tabular}

Tabla 1. Criterios diagnósticos de la ACR y la EULAR de 2010. Manual de la Sociedad Española de Reumatología. Sexta edicioón.

Los criterios para recibir terapia biológica con anti TNF-alfa son:

1. Tener actividad infl amatoria de artritis moderada-alta

2. No haber respondido a una terapia de primera línea (FAMES)

3. Haber sido suspendida por efecto secundario o intolerancia de ésta,

4. No tener enfermedad oncológica activa y no tener una enfermedad desmiel inizante.

La respuesta al tratamiento atenderá a lo siguiente:

1. Medir la actividad inflamatoria de la enfermedad al inicio y a los 3 meses de tratamiento: Esta actividad se medirá con criterios clínicos (número de articulaciones tumefactas y/o dolorosas) y criterios bioquímicos (PCR, VSG) y 
se analiza de forma conjunta utilizando el índice DAS-28. Mediante este índice se puede clasificar a los pacientes en diferentes estadios:

1. Remisión o baja actividad: puntuación menor de 3.2

2. Actividad moderada: puntuación entre 3.2 y 5

3. Alta actividad: puntuación mayor de 5.1.

Además, permite clasificarlos según la mejoría con el tratamiento en: ausente, respuesta moderada o buena respuesta.

Según las recomendaciones internacionales, la respuesta se alcanza a las 4-6 semanas de iniciar pero puede demorarse hasta los tres meses.

c) Criterios de inclusión:

1. Ser diagnosticados de artritis reumatoide según los criterios de la ACR/EULAR.

2. Sexo mujer.

3. Edad superior a 40 años.

4. Presentar moderada o alta actividad inflamatoria según el índice DAS-28.

5. Cumplir criterios de tratamiento con antiTNF-alfa.

6. Aceptar participar en el estudio.

Con estos criterios se recogerían 400 pacientes.

d) Criterios de exclusión:

1. Pacientes con otras enfermedades autoinmunes.

2. Pacientes que hayan sido tratados con antiTNF-alfa anteriormente y que éste haya sido retirado.

3. Estar realizando otro tratamiento de forma concomitante para la artritis reumatoide que sea modificador de la enfermedad (metotrexate, leflunomida, etc).

e) Tamaño muestral: 
Pacientes de la provincia de Granada, cuyo hospital de referencia es el Complejo Hospitalario Universitario de Granada (CHUG), diagnosticados de artritis reumatoide por la Unidad de Gestión Clínica de Reumatología del CHUG, que vayan a ser sometidos a terapia biológica con antiTNF-alfa desde Enero de 2016 a Diciembre de 2017 y que cumplan los criterios de inclusión y exclusión. Consultadas las bases de datos de los últimos 3 años del hospital S. Cecilio, estimamos que en el período de estudio podríamos recoger 400 pacientes con un porcentaje de pérdida del $5 \%$.

\section{d) Variables de estudio:}

Para la recogida de datos se harán dos entrevistas y en cada una de ellas, se procederá a la extracción de sangre para la determinación de miRNA-146 ${ }^{\text {a }}$, la primera antes de iniciar el tratamiento y la segunda a los 3 meses del tratamiento.

Primera entrevista (mes 0):

Se recogerá información sobre edad, raza, el tiempo de evolución de la enfermedad, actividad de la enfermedad, presencia de otros factores que influyen en el pronóstico de la enfermedad como anticuerpos positivos (FR, ACPA), tabaquismo activo, reactantes de fase aguda elevados (PCR, VSG), la presencia precoz de erosiones óseas o defo-

Segunda entrevista (mes 3): se determinará la respuesta al tratamiento según el índice DAS-28 y se realizará la segunda extracción de sangre.

\section{An álisis miR NA-146}

Para valorar si miRNA es un buen biomarcador de respuesta al tratamiento y si se negativiza como respuesta a la terapia se analizará al inicio y a los tres meses de tratamiento.

Para ello, se realizarán dos extracciones de sangre, una al inicio y otra al final del estudio en el laboratorio general, para trasladarla al laboratorio de investigaciones médicas de la unidad de apoyo a la investigación del CHUG y se determinará la expresión de miRNA-146 a en suero mediante la técnica de reacción en cadena de la polimerasa (PCR). Además se analizarán los datos bioquímicos que vamos a tener en cuenta en nuestro estudio como criterios de respuesta al tratamiento (VSG y PCR). Según el protocolo Applied Biosystems, la muestra de sangre extraída será de $5 \mathrm{ml}$, y será inmediatamente transferida a un medio donde sea más estable usando un kit de 
aislamiento de Ribopure-Blood RNA (Applied Biosystems) siendo almacenada a $-20^{\circ} \mathrm{C}$ hasta su utilización.

g) Análisis de datos:

Se describirán las variables de estudio y se estratificarán los resultados en función de variables de confusión.

- La edad se divide en estratos de 5 años.

- El tiempo de evolución de la enfermedad se divide en menos de cinco años y más de cinco años.

- La actividad de la enfermedad clasificará a los pacientes en tres grupos: en remisión, actividad baja, moderada o alta.

\section{h) Limitaciones del estudio:}

1. Se trata de un estudio de base hospitalaria cuyos resultados no podrán extrapolarse a los encontrados por otros investigadores en otras poblaciones.

2. El tamaño muestral es pequeño.

3. El periodo de observación es corto, pues hay algunos pacientes que responden al tratamiento más allá de los 3 meses.

4. El análisis de la respuesta al tratamiento se realiza con un índice muy extendido en la práctica clínica y bastante fiable, pero que incluye criterios subjetivos del paciente como el número de articulaciones dolorosas.

\section{i) Aspectos éticos de la investigación:}

Se valorará el conocimiento de la legislación que regula los aspectos éticos de la investigación y se tomarán las medidas necesarias para conservar el carácter anónimo de los pacientes.

Se requerirá el consentimiento informado para poder almacenar su sangre y analizarla en los términos que indica el proyecto. La muestra podrá ser destruida a petición del interesado y/o cuando acabe el proyecto para lo que ha sido requerida. Todo ello atendiendo a la legislación vigente sobre muestras biológicas. 


\section{BIBLIOGRAFÍA:}

1. Firestein GS. Etiology and Pathogenesis of Reumatoid Arthritis. En: Firestein GS, Budd RC, Gabriel SE, IB McInnes, O’Dell JR, editors. Kelley’s Textbook of Rheumatology, 9th ed. Philadelphia, Elsevier Saunders, 2005; 1059-108.

2. Churov A, Oleinik E, Knip M. MicroRNAs in rheumatoid arthritis: altered expression and diagnostic potential. Autoinmun Reviews 2015; 1741-1750.

3. Muller-Ladner U, Pap T, Gay RE, Neidhart M, Gay S. Mechanisms of disease: the molecular and cellular basis of joint destruction in rheumatoid arthritis. Nat Clin Pract Rheumatol 2005; 1: 102-10.

4. Pablos JL, Cañete JD. Immunopathology of rheumatoid arthritis. Curr Top Med Chem 2013; 13: 705-11

5. Castro-Villegas C, Pérez-Sánchez C, Escudero A et al. Circulating miRNAs as potential biomarkers of therapy effectiveness in rheumatoid arthritis patientes treated with antiTNFalfa. Arthritis research \& therapy, 2015; 17: 49-64.

6. Burmester GR, Pratt AG, Scherer HU, Van Laar JM. Rheumatoid Arthritis: Pathogenesis and Clinical Features. En: Bijilsma JWJ, editor. Eular Textbook on Rheumatic Diseases. London, BMJ Publihsing Group Ltd., 2012; 206-31.

7. Harris ED. Manifestaciones clínicas de la artritis reumatoide. En: Kelley Tratado de Reumatología. Versión en español de la 7. a edición inglesa. Madrid, Elsevier, 2006; 1053-88.

8. Mc Queen FM, Ostergaard M. Established Rheumatoid Arthritis - new imaging modalities. Best Pract Res Clin Rheumatol 2007; 21: 841-56.

9. Michaudn K, Wolfe F. Comorbidities in rheumatoid arthritis. Best Pract Res Clin Rheumatol 2007;21: 885-906.

10. Navarro Sarabia F, Ballina García FJ, Hernández Cruz R, Hernández Mejía R, Ruiz Montesinos MD, Fernández López JA et al. Costes calidad de vidaartritis reumatoide. 
Estudio económico y de la calidad de vida de los pacientes con Artritis Reumatoide en España. Resultados preliminares. Rev Esp Reumatol 2004; 31: 184-9.

11. Gorter SL, Bijlsma JW, Cutolo M, Gomez-Reino J, Kouloumas M, Smolen JS et al. Current evidence for the management of rheumatoid arthritis with glucocorticoids: a systematic literature review informing the EULAR recommendations for the management of rheumatoid arthritis. Ann Rheum Dis 2010; 69: 1010-4

12. Shahouri SH, Michaud K, Mikuls TR, Caplan L, Shaver TS, Anderson JD et al. Remission of rheumatoid arthritis in clinical practice: application of the American College of Rheumatology/European League Against Rheumatism 2011 remission criteria. Arthritis Rheum 2011; 63: 3204-15.

13. Singh JA, Furst DE, Bharat A, Curtis JR, Kavanaugh AF, Kremer JM et al. 2012 update of the 2008 American College of Rheumatology recommendations for the use of disease -modifying antirheumatic drugs and biologic agents in the treatment of rheumatoid arthritis. Arthritis Care Res (Hoboken) 2012; 64:625-39.

14. Smolen JS, Aletaha D, Bijlsma JW, Breedveld FC, Boumpas D, Burmester G et al; T2T Expert Committee. Treating rheumatoid arthritis to target: recommendations of an international task force. Ann Rheum Dis 2010; 69: 631-7.

15. Smolen JS, Landewé R, Breedveld FC, Buch M, Burmester G, Dougados M et al. EULAR recommendations for the management of rheumatoid arthritis with synthetic and biological disease-modifying antirheumatic drugs: 2013 update. Ann Rheum Dis 2014; 73: 492-509.

16. Van der Helm-van Mil AH, Huizinga TW. The 2010 ACR/EULAR criteria for rheumatoid arthritis: do they affect the classification or diagnosis of rheumatoid arthritis? Ann Rheum Dis 2012; 71: 1596-8.

17. Smolen JS, Steiner G. Therapeutic strategies for rheumatoid arthritis. Nat Rev Drug Discov 2003; 2: 473-88. 
18. Aletaha D, Neogi T, Silman AJ, Funovits J, Felson DT, et al. Rheumatoid arthritis classification criteria: an American College of Rheumatology/European League Against Rheumatism collaborative initiative. Arthritis Rheum 2010; 62: 2569-81.

19. Belmonte MA. Is the DAS28 Score the Most Adequate Method to Estimate Activity in Rheumatoid Arthritis? Clinimetric Considerations and Simulations Scenarios. Reumatol Clin 2008; 4:183-90.

20. Salehi E, Eftekhari R, Oraei M, Gharib A, Bibab K. MicroRNAs in rheumatoid arthritis. Clin Rheumatol 2015; 34: 615-628.

21. Ha M, Kim VN. Regulation of microRNA biogénesis. Nat Rev Mol Cell Biol 2014; 509 $-24$.

22. Pauley KM, Satoh M, Chan AL, Bubb MR, Reeves WH, Chan EK. Upregulated miR146a expression in peripheral blood mononuclear cells from rheumatoid arthritis patientes. Arthritis Rhes Ther 2008; 10(4): R101.

23. Murata K, Yoshitomi H, Tanida S, Ishikawa M, Nishitani K, Ito H, Nakamura T. Plasma and sinovial fluid microRNAs as potential biomarkers of rheumatoid arthritis and osteoarthritis. Arthritis Res Ther 2010; 12 (3):R86.

24. Filkova M, Jüngel A, Gay RE, Gay S. MicroRNAs in Rheumatoid Arthritis. Biodrugs 2012; 26(3): 131-141.

25. Chen X, Huang Q, Yang S, Chu Y, Yan H et al. Role of MicroRNAs in the Pathogenesis of Rheumatoid Arthritis. Medicine 2015; 94 (31): e1326.

26. Ceribelli A, Nahid M, Satoh M, Chan E. MicroRNAs in rheumatoid arthritis. FEBS letters 2011; 585: 3667-3674.

27. Ammari M, Jorgensen C, Apparailly F. Impact of microRNAs on the urnderstanding and treatment of rheumatoid arthritis. Inmunopathogenesis and treament of autoinmune diseases $2013 ; 25(2): 225-233$. 